\title{
SIG-WEB CEARÁ EM MAPAS INTERATIVOS, NOVAS FERRAMENTAS NA CARTOGRAFIA ESCOLAR
}

\author{
WEB-GIS Ceará for Interactive Maps, new tools in cartographic education
}

\author{
Emanuel Lindemberg Silva Albuquerque* \\ Cleyber Nascimento de Medeiros** \\ Daniel Dantas Moreira Gomes*** \\ Maria Lúcia Brito da Cruz****
}

\begin{abstract}
Resumo
Este artigo propõe abordar novas perspectivas para o ensino-aprendizado na Geografia, tendo como viés de análise uma infraestrutura de dados espaciais georreferenciados na internet. O objetivo central é compreender a importância do SIG-WEB Ceará em Mapas Interativo como uma ferramenta de significativa importância para o ensino. A metodologia está baseada em uma averiguação do que dispõe a Lei de Diretrizes e Bases da Educação - LDB e dos Parâmetros Curriculares Nacionais - PCN's a respeito da aplicação das Tecnologias da Informação e Comunicação - TIC no ensino. Conclui-se que as ferramentas disponíveis no mencionado SIG-WEB constituem-se em um instrumento que se mostra com um potencial elevado no processo de aprendizagem na Geografia e em áreas afins, tendo em vista uma diversificada base de dados de temas socioeconômicos e cartográficos.
\end{abstract}

Palavras-chave: Cartografia, Ensino-aprendizagem, Ceará em Mapas Interativo, Internet.

\begin{abstract}
This article proposes to address new opportunities for teaching and learning in Geography, with the bias analysis of an infrastructure of spatial data georeferenced on the Internet. The central objective is to understand the importance WEB-GIS Ceara System for Interactive Maps as a significant tool importance for teaching. The methodology is based on an investigation of available to the Law of Directives and Bases of Education - LDB and Parameters National Curriculum - PCN's about the application of technologies Information and Communication - ICT in education. We conclude that the tools available on WEB-GIS is mentioned in an instrument that shows with a high potential in the process of learning in Geography and related areas, aimed at a diverse database of themes socioeconomics and cartographies.
\end{abstract}

Key words: Cartography, Teaching-learning, Ceara System for Interactive Maps, Internet.

\section{Résumé}

Cet article se propose d'aborder de nouvelles opportunités pour l'enseignement et l'apprentissage dans Géographie, comme ayant un biais dans l'analyse de l'infrastructure de données spatiales géoréférencées sur l'Internet. L'objectif principal est de comprendre l'importance WEB-SIG des cartes interactives du Ceará comme un outil important importance à l'éducation. La méthodologie est basée sur une enquête sur les disponibles à la loi des directives et des bases de l'éducation - LDB et paramètres National Curriculum - PCN sur l'application des technologies Information et communication - TIC dans l'enseignement. Nous concluons que les outils disponibles sur le WEB-SIG est mentionné dans un instrument qui montre un fort potentiel dans le processus d'apprentissage en géographie et en domaines connexes, avec une base de données en vue de divers thèmes données socio-économiques et cartographiques.

Mots clés: :Cartographie. L'enseignement et l'apprentissage. Cartes interactives de Ceará. Internet.

(*) Mestrando em Geografia dla Universidade Estadual do Ceará - Av. Paranjana 1700 BLOCO C-sala 01 e E sala 03, CEP: 60.740-000 - Fortaleza (CE) - Brasil. Tel./Fax: (+55 85) 31019774 / 31019780 - emanuel.silva@ipece.ce.gov.br

(**) Doutorando em Geografia da Universidade Estadual do Ceará - Av. Paranjana 1700 BLOCO C-sala 01 e E sala 03, CEP: 60.740-000 - Fortaleza (CE) - Brasil. Tel./Fax: (+55 85) 31019774 / 31019780 - cleyber.medeiros@ipece.ce.gov.br

(***) Doutorando em Geologia da Universidade Federal do Ceará - Campus do Pici - Bloco 912, CEP: 60445-760 - Fortaleza (CE) - Brasil. Tel: (+55 85) 33669867 - daniel.dantas@ipece.ce.gov.br

$(* * * *) P^{2} f^{a}$. Dr ${ }^{\mathrm{a}}$. da Pós-Graduação em Geografia da Universidade Estadual do Ceará - Av. Paranjana 1700 BLOCO C-sala 01 e E sala 03, CEP: 60.740-000 - Fortaleza (CE) - Brasil. Tel./Fax: (+55 85) 31019774 / 31019780 - mlbcruz@gmail.com 


\section{INTRODUÇÃO}

Ao se enfatizar a cartografia escolar como uma ferramenta que se mostra com grandes potencialidades e dinamicidade para o ensino-aprendizagem na Geografia, bem como em outras áreas afins, nota-se que esse viés de análise e reflexão é fruto dos avanços das tecnologias geoinformacionais proporcionadas pelo mundo moderno, materializadas pelas mais diversas Tecnologias de Informação e Comunicação - TIC.

Em virtude dos avanços técnico-científicos, observa-se nos dias atuais o aumento expressivo na disponibilização de dados na Internet, de modo a facilitar o acesso aos mais diversos tipos de dados, tendo em vista as inovações proporcionadas com as novas e modernas ferramentas tecnológicas, que têm beneficiado o incremento e o uso de novos instrumentos (MOREIRA, 2010).

Nesse sentido, o presente artigo propõe abordar novas técnicas para a cartografia escolar, tendo em vista a importância da espacialização das variáveis socioambientais na compreensão do espaço geográfico de maneira totalizante e de forma integralizada das relações sociedade e natureza, na perspectiva da geração de produtos cartográficos de qualidade e sem nenhum custo financeiro adicional. Salienta-se que a Internet é uma robusta ferramenta que pode ser utilizada nos mais longínquos territórios e com alcance a nível global.

Objetiva-se nesse artigo compreender a importância do Sistema de Informações Geográficas para Internet (SIG-WEB) Ceará em Mapas Interativo (http://mapas.ipece.ce.gov.br), desenvolvido pelo Instituto de Pesquisa e Estratégia Econômica do Ceará - IPECE como um instrumento de significativa importância para o ensino-aprendizado da Geografia no que concerne a cartografia escolar, em particular da Geografia do Ceará, nos níveis fundamental e médio das escolas públicas e particulares do Estado.

A metodologia está baseada numa averiguação do que dispõe a Lei n ${ }^{\circ}$. 9.394, de 20 de dezembro de 1996, que estabelece as Diretrizes e Bases da Educação Nacional - LDB (BRASIL, 1996), e dos Parâmetros Curriculares Nacionais - PCN's da disciplina de Geografia (BRASIL, 1998) a respeito da utilização das Tecnologias da Informação e Comunicação - TIC nos estabelecimentos educacionais, bem como das possibilidades de aplicabilidades do mencionado SIG-WEB nas mais diversas temáticas inerentes a prática de ensino-aprendizagem de Geografia. Corrobora-se que o Ministério da Educação - MEC juntamente com os Estados, Prefeituras e terceiro setor estão promovendo a diminuição da distância do cidadão comum e o uso das novas TIC, trabalhando na tendência da inclusão digital como direito do cidadão. Neste contexto, Junqueira (2008) destaca que,

As Tecnologias da Informação e da Comunicação (TIC), além de apontar o desafio da necessidade de promoção da inclusão digital, o que depende basicamente de políticas públicas específicas, não do papel do professor, apontam nos meios educacionais novos rumos de trabalho didático. Cabe aos educadores utilizar adequadamente os recursos oferecidos por essas tecnologias e explorar seu potencial pedagógico, tendo em vista a configuração de novos ambientes de ensino-aprendizagem. A inserção das tecnologias em projetos de aprendizagem abre perspectivas de mudanças na escola, aproximando-as das expectativas dos jovens e adolescentes naquilo que lhes pode ser oferecido. (JUNQUEIRA, 2008, p. 8-9).

Vale salientar que nas últimas décadas observou-se o crescente número de ferramentas envolvendo a informática e as novas TIC, que apareceram como novas possibilidades no ensino em todos os níveis e áreas do conhecimento, bem como de que o papel do professor não é somente de detentor dos conhecimentos, mas também de um orientador e de um instigador da pesquisa e da busca, fornecendo ao aluno instrumentos que lhe permitam buscar novos saberes que garantam uma compreensão do mundo e da sociedade na qual está inserido dentro do contexto da contemporaneidade. 
O crescente avanço da informática tem possibilitado e estimulado a evolução das chamadas geotecnologias, propondo uma integração entre o método convencional de se ensinar geografia e o uso de tecnologias que utilizam técnicas matemáticas e computacionais para a manipulação e sistematização de informações geográficas, levando em consideração a atual facilidade em se conseguir mapas digitais interativos, imagens de satélites e outros dados via internet.

Além dos avanços expressivos no campo informacional e tecnológico, como destaca Medeiros et al. (2010), podemos referenciar o geoprocessamento e os Sistemas de Informações Geográficas - SIG's que, aliados à Internet, tornaram-se tecnologias ainda mais robustas para divulgar os mais diversos tipos de informações. Essa tecnologia permite a utilização de técnicas matemáticas e computacionais para a coleta, armazenamento e processamento de dados geográficos, que aliadas às TIC poderão atribuir novas metodologias ao ensino-aprendizagem.

O Ceará em Mapas Interativo trata-se de um Sistema de Informação Geográfica para internet, capaz de realizar consultas e análises utilizando dados georreferenciados e cartográficos do Estado do Ceará, tais como: limites e regionalizações; imagens de satélite; ortofotos; mapas de indicadores socioeconômicos; mapa das áreas degradadas; mapa das unidades fitoecológicas; mapa das unidades geoambientais; mapa dos tipos climáticos; mapa dos recursos hídricos; entre outros dados que são essenciais para compreender a relação sociedade-natureza numa perspectiva de integração das variáveis naturais, sociais e econômicas.

O sistema foi concebido e estruturado em softwares livres, apresentando uma interface amigável e aliado a uma alta performance, com recursos e ferramentas de grande potencial no ensino-aprendizagem da disciplina de Geografia e/ou das demais áreas de conhecimento.

Utilizando o Sistema como um instrumento para a cartografia escolar e, conseqüentemente, como uma prática de ensino-aprendizado de Geografia, os professores e alunos podem fazer consultas aos dados e informações georreferenciadas, modificar os mapas gerados bem como salvar os mesmos em diversos formatos de arquivo, sendo assim um sistema interativo, dinâmico e com uma base de dados atualizada e disponível para toda a sociedade, além de subsidiar os gestores públicos no planejamento de políticas públicas e na tomada de decisão (MEDEIROS et al., 2010).

Neste mesmo viés de análise, é possível trabalhar as mais diversas facetas da cartografia escolar dentro do SIG-WEB desenvolvido pelo IPECE, como as noções de proporção e escala, de coordenadas geográficas, de sistema de projeção, de sensoriamento remoto, de geoprocessamento; dentre outras possibilidades da representação didática do espaço geográfico até chegar à síntese do mapeamento.

A partir dessa perspectiva, a cartografia escolar pode dar um salto de qualidade no ensino-aprendizado de Geografia, tendo em vista que a interatividade facilita a leitura e a interpretação das mais diversas variáveis espaciais, permitindo um domínio e melhor compreensão do espaço geográfico de maneira mais consistente e pertinente, pois a melhor forma de sintetizar uma informação geográfica é através de sua espacialização no tempo e no espaço. É nesse contexto que propomos uma reflexão da aplicabilidade do SIG na Educação.

\section{DESENVOLVIMENTO CONCEITUAL: da cartografia clássica à digital; dos mapas estáticos aos interativos}

Com a crescente utilização das geotecnologias nas mais diversas áreas do conhecimento, muitas instituições de ensino e pesquisa vêm produzindo grandes quantidades de dados georreferenciados. Contudo, a disponibilização destes dados para a sociedade ocorre ainda de maneira pouco eficiente, gerando uma demanda pela busca de informações que não podiam ser publicadas ou disponibilizadas eficientemente devido à falta de recursos e domínio tecnológico. 
No entanto, com o constante desenvolvimento da internet esta se proveu de recursos gráficos, tornando-se um meio atraente e eficiente para a disseminação de dados georreferenciados para serem aplicados na cartografia escolar do ensino fundamental e médio, tanto no ensino público quanto no ensino privado.

Com o avanço da tecnologia da informação nos últimos anos tem-se o advento da passagem da cartografia clássica para a digital através da utilização dos Sistemas de Informações Georreferenciadas (SIG's), permitindo uma disponibilização mais eficaz da geoinformação (MEDEIROS et al., 2010).

Segundo Hubner e Oliveira (2008), a geração, utilização e publicação de informações georreferenciadas (geoinformação) tem sido importante para diversas atividades humanas, pois a análise espacial de fenômenos geográficos é uma forte aliada nas ações de planejamento, gestão e superação de problemas. No entanto, para que estudantes e gestores possam tomar conhecimento e decisões seguras a partir de uma geoinformação, é necessário que eles tenham qualidade e facilidade de acesso, como também de que os dados georreferenciados sejam confiáveis.

Nos últimos anos tem-se o advento da passagem da cartografia clássica para a cartografia digital através da utilização dos SIG's, permitindo uma disponibilização mais eficaz da geoinformação. Conforme Burrough (1987), os SIG's são constituídos por um conjunto de ferramentas especializadas em adquirir, armazenar, recuperar, transformar e emitir informações espaciais (mapas) através da análise de dados georreferenciados. De acordo com Xavier-da-Silva (2001), um SIG consiste em um sistema capaz de operar sobre seus dados, reestruturando-os para ganhar conhecimento sobre posições, extensões e relacionamentos taxonômicos, espaciais e temporais contidos em suas bases de dados.

Para Câmara et al. (2005), é possível indicar entre as principais características dos SIG's a capacidade de inserir e integrar, em uma única base de dados, informações espaciais provenientes de dados cartográficos, censitário e cadastro urbano e rural, imagens de satélites, redes e modelos numéricos do terreno, oferecendo mecanismos para combinar as várias informações através de algoritmos de manipulação e análise, bem como para consultar, recuperar, visualizar e plotar conteúdo da base de dados georreferenciada, proposta essa idealizada pelo SIG-WEB Ceará em Mapas Interativo como uma nova ferramenta para a cartografia escolar.

De acordo com Sancho (1998), a prática docente deve responder às questões reais dos estudantes, que chegam até ela com todas as suas experiências vitais e deve utilizar-se dos mesmos recursos que contribuíram para transformar suas mentes fora dali. Desconhecer a interferência da tecnologia, dos diferentes instrumentos tecnológicos, na vida cotidiana dos alunos é retroceder a um ensino baseado na ficção.

Vale salientar que a internet, no início da década de 1990, ainda era de uso restrito, mas que hoje está presente na vida da maioria das pessoas e em quase $100 \%$ dos estabelecimentos de ensino, o que vem alterando radicalmente hábitos de comunicação, entretenimento, negócios e pesquisas, prometendo ainda mudanças significativas e imprevisíveis para a humanidade.

Conforme Câmara et al. (1996), a internet rapidamente se tornou o meio preferencial para disseminação de dados. Sua (quase) universalidade, associada a custos de acesso cada vez mais baixos, motivou o desenvolvimento de toda uma nova classe de sistemas de informação, com uma arquitetura diferenciada em relação a seus predecessores.

Existem basicamente dois métodos (estáticos e interativos) para trabalhar com a cartografia escolar na internet, que diferem entre si em relação à forma de execução. Os mapas estáticos são disponibilizados na forma de imagem, não permitindo alteração de escala e de mapas visualizados, sendo úteis para usuários que desejam ter um mapa pronto. Já os mapas interativos integram informações de um banco de dados a elementos georreferenciados, possibilitando a obtenção posterior 
desta informação a partir de um clique do mouse sobre este elemento, consentindo: localizar objetos geográficos e realizar filtros através de seus atributos; executar operações de zoom e alteração de escala; adicionar e retirar mapas na forma de camadas para serem visualizadas; efetuando assim operações de consulta e análise através de menus interativos do mapa, características essas primordiais no ensino-aprendizado da cartografia escolar com aplicabilidade na ciência geográfica.

Vale corroborar que a palavra interatividade é derivada do vocábulo inglês interactivy, e começou a ser usada por pesquisadores da área de informática a partir da década de 1960 para assinalar uma nova qualidade da computação (MOREIRA, 2010). O termo foi criado para enfatizar uma mudança qualitativa na relação do usuário com o computador, na medida em que foram incorporados dispositivos de entrada e saída de dados nos sistemas computacionais, que permitiram a interação homem-máquina (FRAGOSO, 2001).

Segundo Silva (2007), levar a informação espacial para internet é uma das tendências alcançadas no contexto da democratização cartográfica escolar, neste sentido, a disponibilização de dados espaciais na internet possibilita uma nova realidade através de aplicações SIG, representando uma evolução dos SIG's desktop para os SIG's distribuídos na rede mundial de computadores.

Um SIG para ambiente web é definido em Ribeiro e Câmara (2003) como um SIG de $3^{\text {a }}$ Geração, caracterizado como um banco de dados geográfico compartilhado por um conjunto de instituições, acessível remotamente, por meio da internet, capaz de armazenar, além dos dados geoespaciais, as descrições acerca dos dados (metadados) e documentos multimídia associados (texto, fotos, áudio e vídeo).

Neste sentido é que o SIG-WEB Ceará em Mapas Interativo visa atender, primordialmente, a sociedade escolar, disponibilizando informações georreferenciadas e cartográficas sobre as áreas social, econômica, ambiental e territorial do Estado do Ceará, pretendendo-se manter constantemente atualizado e acessível na perspectiva de se consolidar como uma ferramenta para a cartografia escolar no contexto da Geografia no Ceará.

O avanço da informática tem possibilitado e estimulado uma evolução das chamadas geotecnologias, que são tecnologias que utilizam técnicas matemáticas e computacionais para a manipulação e sistematização de informações geográficas. E devido a essa necessidade de inserir nas escolas a evolução vivenciada pela nossa sociedade moderna tecnológica, os PCN's e as diretrizes para o ensino médio, passaram a destacar a importância de se trabalhar com o conhecimento cientifico e tecnológico, no ensino médio e fundamental, favorecendo assim a introdução das geotecnologias, no âmbito escolar (BRASIL, 1998).

Os PCN's do Ensino Médio, ao tratarem as competências e habilidades a serem desenvolvidas na disciplina de Geografia, expressam entre elas a representação e comunicação, especificamente enfatizando "Ler, analisar e interpretar os códigos específicos da Geografia (mapa, gráficos, tabelas e etc.)" (BRASIL, 1999, p.315).

Conforme orientação dos PCN's, o direcionamento das tecnologias para o ensino-aprendizado da Geografia, em particular da cartografia escolar, permite o uso desses ambientes para a pesquisa de dados e aplicativos e, ainda, para o tratamento das informações, construção de gráficos, tabelas, realização de cálculos e mapeamentos, como citado anteriormente. Atualmente os PCN's para o ensino de Geografia incluem a linguagem cartográfica como conteúdo obrigatório.

De acordo com Ramos e Sanches,

[...] o documento cartográfico, quando corretamente construído, pode apontar tendências, hipóteses, fenômenos, que não seriam visíveis apenas em uma tabela de dados. Muitas vezes um mapa bem construído pode comunicar de imediato ao leitor um fenômeno descrito em várias páginas de texto. O mapa não se restringe apenas a uma ilustração, ele é de fato um instrumento de análise. (RAMOS e SANCHES, 2000, p.50). 
Atualmente, devido às inovações geotecnológicas, a apresentação e disponibilidade de dados geográficos pela Internet contribuem no ensino, na difusão e na curiosidade pelo conhecimento geográfico e no reconhecimento e criação de uma identidade.

Inicialmente, apresenta-se na Figura 1 a interface do mencionado SIG-WEB, mostrando a área do Mapa com os municípios cearenses e a espacialização das sedes municipais, visualizando-se na margem esquerda as Guias Temas composta pela distribuição dos Temas vetores, os Temas socioeconômicos e os Temas imagens, com os seus respectivos subtemas. Na parte superior, encontra-se o Menu Superior e a Barra de Ferramenta e na parte inferior, o Rodapé, com destaque para a escala de trabalho e as coordenadas geográficas.

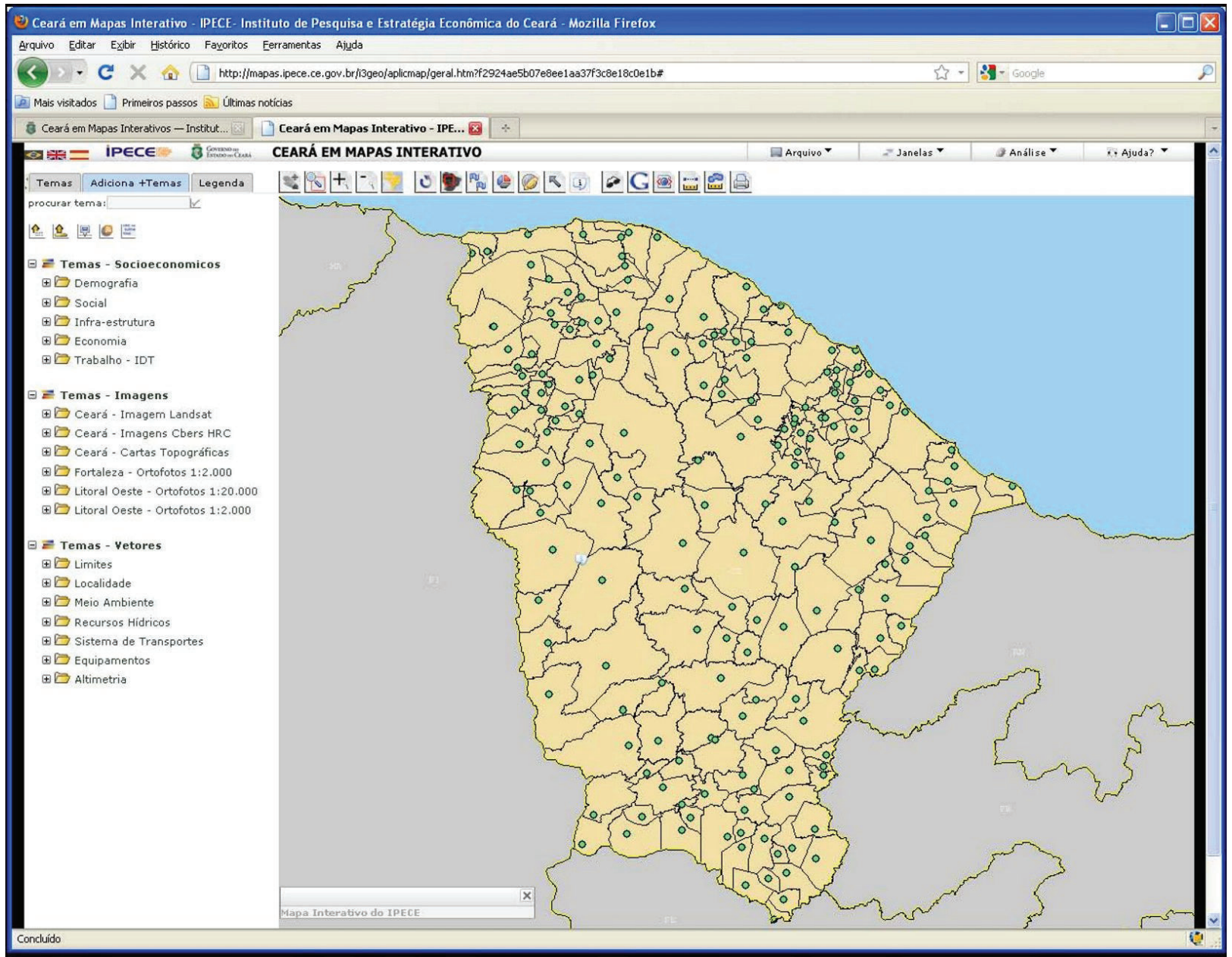

Figura 1 - Interface inicial do SIG-WEB Ceará em Mapas Interativo.

Na perspectiva de trabalhar com a cartografia escolar no contexto da interatividade, são descritas no Quadro 1 as funções disponíveis na Barra de Ferramentas do Sistema Ceará em Mapas Interativo, onde a partir das mesmas o usuário pode visualizar os mapas na forma de camadas; efetuar operações de zoom e mudança de escala; inserir coordenadas geográficas; medir distâncias e calcular áreas; localizar objetos geográficos e consulta a seus atributos; realizando assim operações de consulta e análise através de menus interativos do mapa.

A relevância desta proposta metodológica está justamente no seu propósito de aumentar o poder analítico das informações contidas no banco de dados (verdadeiras caixas-pretas em algumas instituições) o que, conseqüentemente, resultará numa ampliação do conhecimento sobre um tema 
abordado. E quanto maior o conhecimento, maiores são as possibilidades para se resolverem os problemas.

Para Medeiros et al. (2010), a eficiência da gestão publica exige dos gestores um amplo conhecimento de seu território com informações e dados atualizados que mostrem as várias realidades que existem, suas potencialidades e principalmente os problemas que precisam ser solucionados em determinadas áreas.

Dentre as possibilidades proporcionadas pelo SIG-WEB na área da Educação, pode-se frisar as técnicas e ferramentas de sensoriamento remoto e geoprocessamento com múltiplas finalidades. Junqueira (2006) ressalta alguns usos do sensoriamento remoto nas disciplinas abordadas no ensino médio e fundamental como, por exemplo: Em Geografia: auxilia em assuntos ligados a análise espacial e interpretação de mapas; Em História: auxilia a análise comparativa de interpretação de imagens de uma mesma região em períodos diferentes, permitindo realizar um elo da história espacial da área de estudo; Em Matemática: cálculo de áreas urbanas, escalas, taxa de crescimento do desmatamento de certa região, distâncias ente feições de interesse, entre outras análises.

Quadro 1 - Funções disponíveis na Barra de Ferramentas do Ceará em Mapas Interativo

\begin{tabular}{|c|c|}
\hline FUNCAO & DESCRICAO \\
\hline & $\begin{array}{l}\text { A ferramenta de Pan é responsável pela movimentação do mapa, ou seja, com esta } \\
\text { ferramenta o usuário pode navegar pelo mapa, posicionando-o na área desejada para } \\
\text { torná-la visível. }\end{array}$ \\
\hline & $\begin{array}{l}\text { Possibilita a ampliação do mapa a partir de um zoom em determinada região indicada } \\
\text { pela construção de um retângulo. }\end{array}$ \\
\hline & Possibilita aumentar o zoom da área do mapa. \\
\hline & Possibilita diminuir o zoom da área do mapa. \\
\hline & Altera a escala do mapa ajustando-a para a área de abrangência do Estado do Ceará. \\
\hline & Reinicia o sistema com as configurações iniciais. \\
\hline & Abre ou fecha o mapa de referência. \\
\hline & Insere pontos no mapa a partir de coordenadas geográficas. \\
\hline & Insere um gráfico no ponto escolhido conforme atributos do tema escolhido. \\
\hline & Insere texto no mapa clicando em um determinado local do mapa. \\
\hline & Abre as ferramentas para seleção de elementos de um tema. \\
\hline i) & Consulta informações do banco de dados dos temas exibidos no mapa. \\
\hline 8 & Abre lente de ampliação. \\
\hline & $\begin{array}{l}\text { Abre o Google Maps, mostrando uma imagem de satélite da região vista no mapa } \\
\text { principal. }\end{array}$ \\
\hline 103 & Mostra a extensão geográfica atual do mapa em coordenadas geográficas. \\
\hline … & Mede a distância entre dois ou mais pontos clicados no mapa. \\
\hline 要 & Mede a área de um polígono desenhado no mapa. \\
\hline 国 & Imprime o mapa no formato PDF ou TIFF. \\
\hline
\end{tabular}

Fonte: SIG-WEB Ceará em Mapas Interativo do IPECE. Elaboração dos autores. 
Nas figuras seguintes $(2,3,4,5,6,7$ e 8) são mostrados alguns exemplos da utilização do Sistema Ceará em Mapas Interativo para consulta, análise e tratamento dos dados georreferenciados disponíveis, que têm como viés a cartografia escolar com aplicabilidade para o ensino-aprendizado de Geografia.

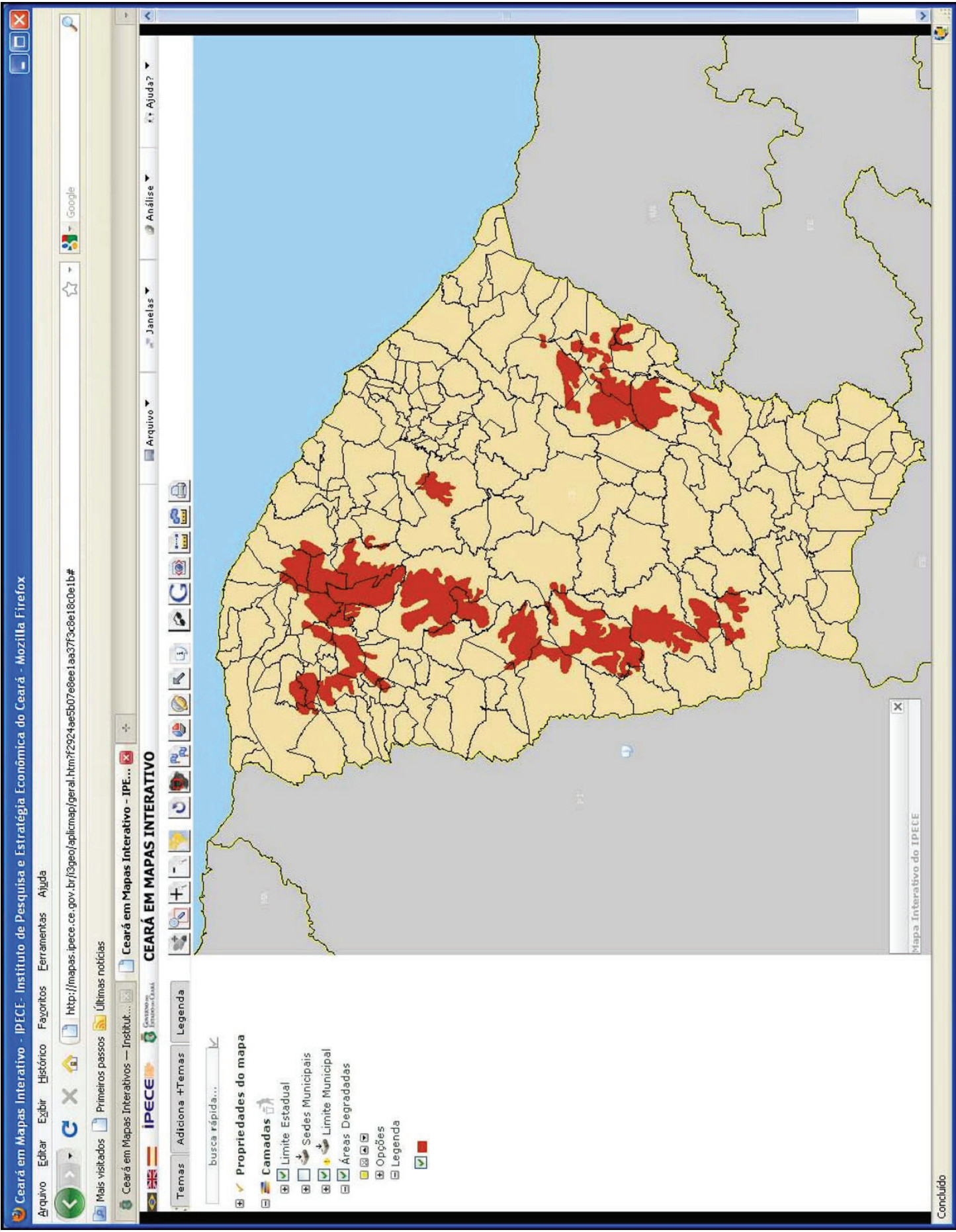

Figura 2 - Áreas degradadas e susceptíveis a desertificação no Estado do Ceará 


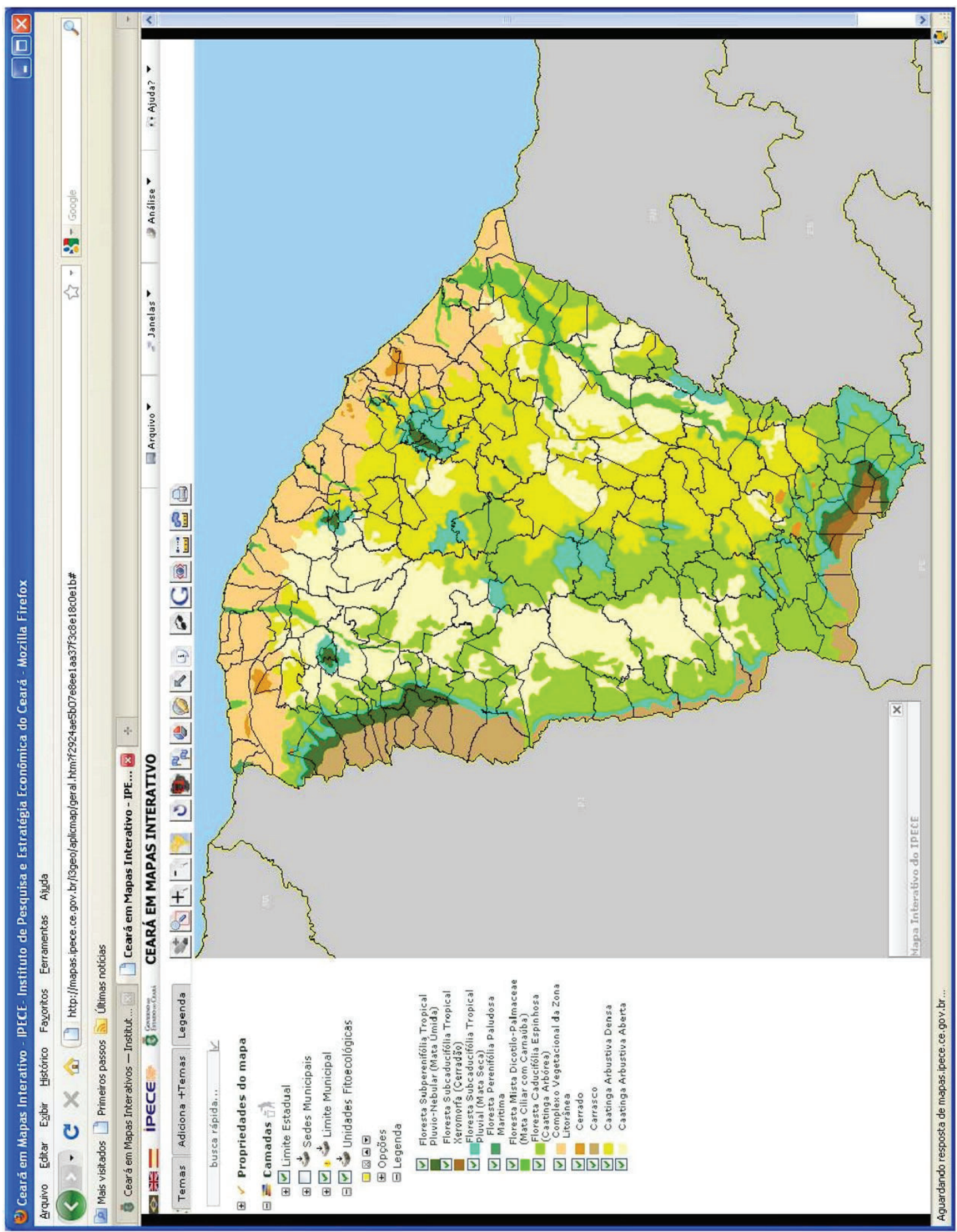

Figura 3 - Unidades fitogeográficas, que pode auxiliar ao professor a ensinar aos alunos sobre a localização dos diversos tipos de vegetação existentes no Ceará. 
ALBUQUeRQUE, E. L. S.; MEDEIROS, C. N.; GOMES, D. D. M.; CRUZ, M. L. B.

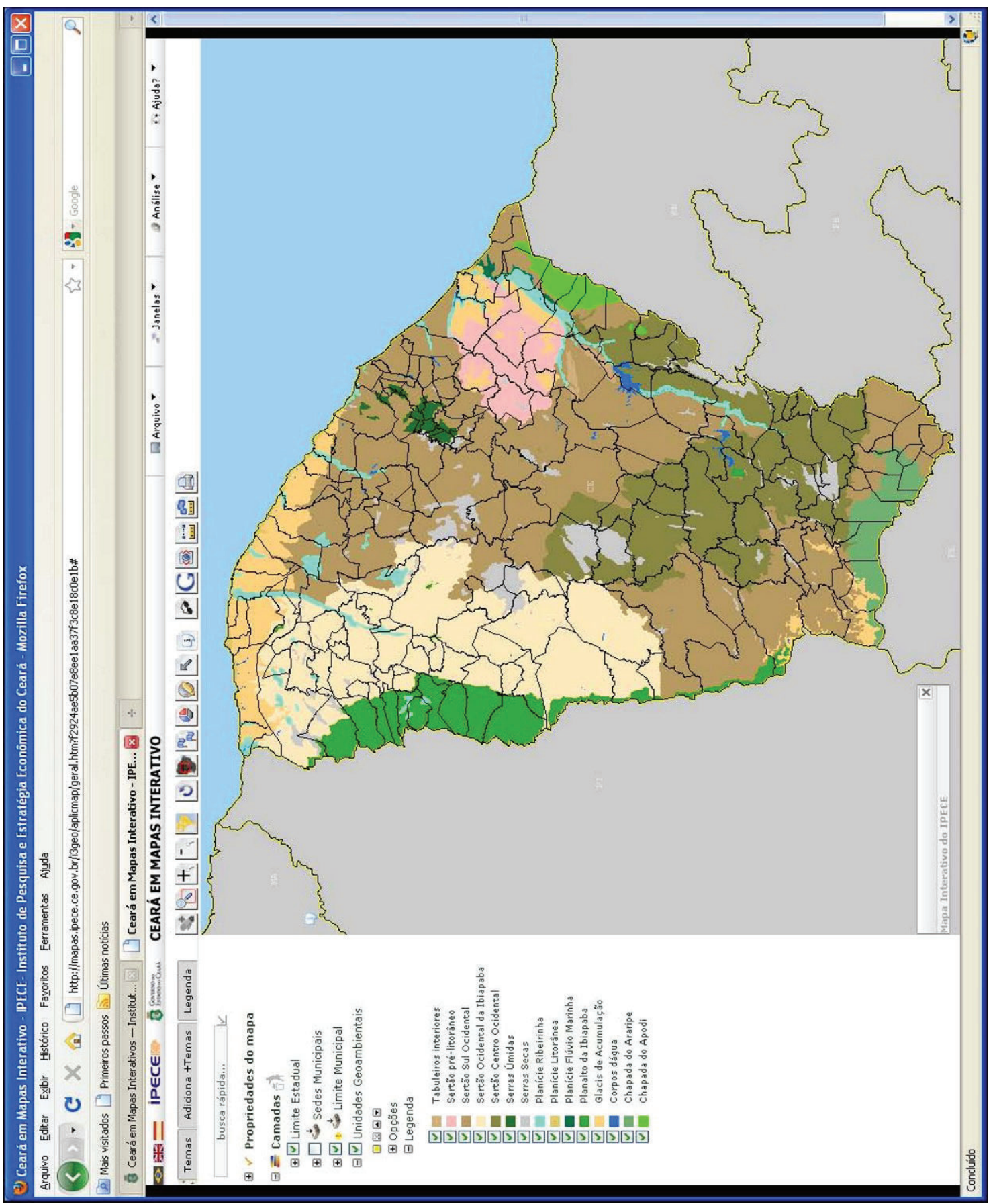

Figura 4 - Unidades geoambientais do Estado do Ceará. 


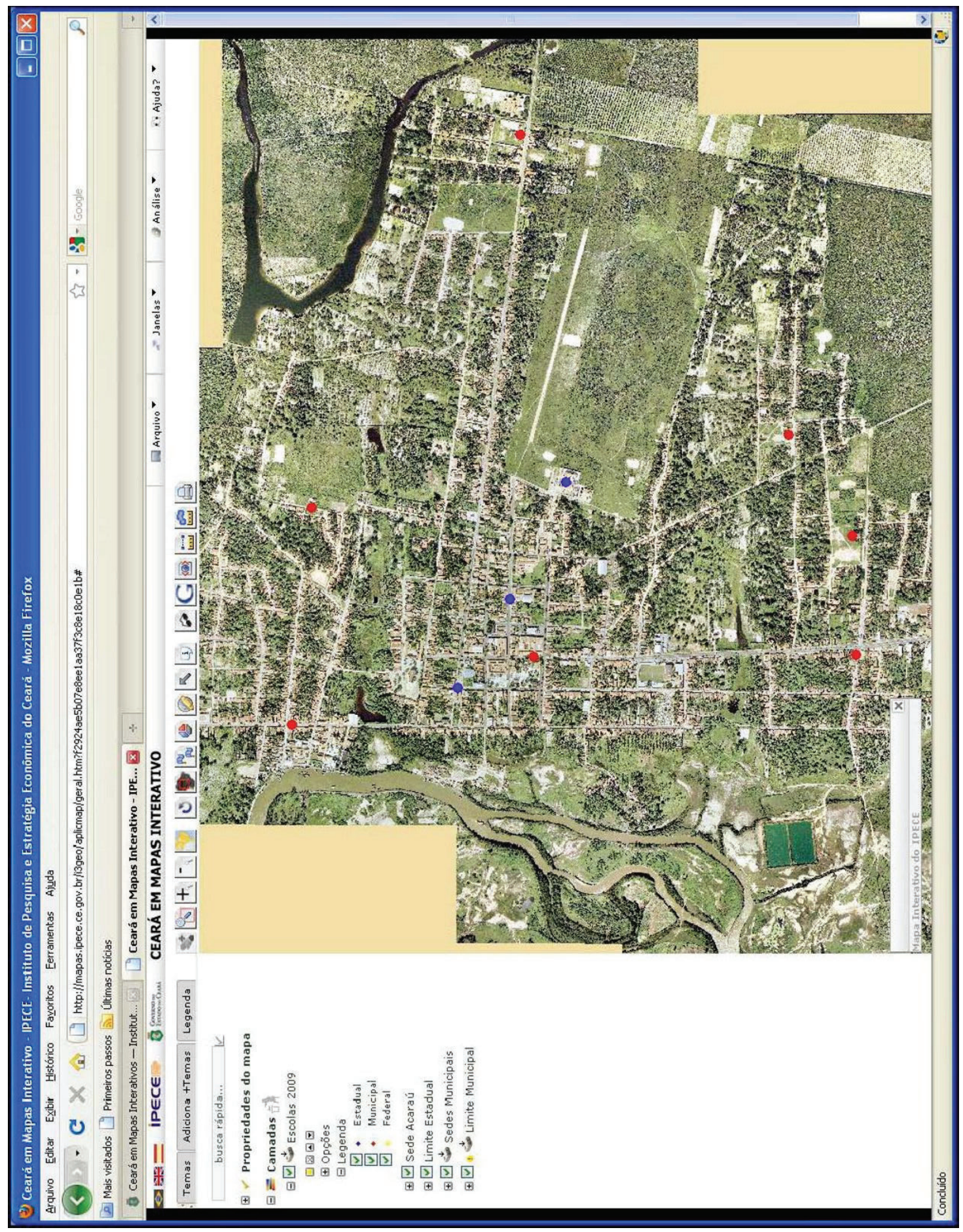

Figura 5 - Ortofoto na escala de 1:2.000 do Município de Acaraú/CE, destacando a localização das escolas. 


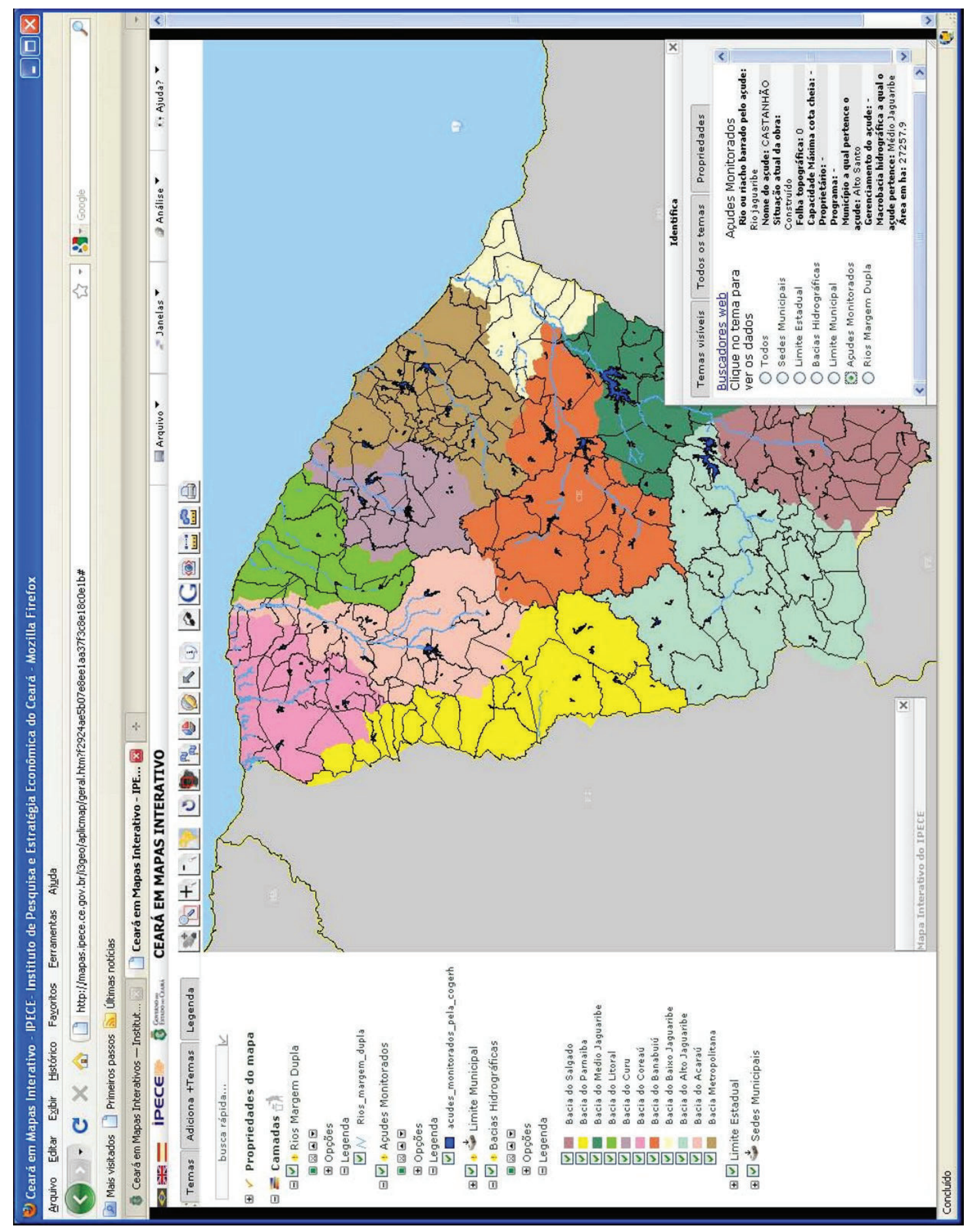

Figura 6 - Açudes monitorados nas Bacias Hidrográficas com consulta ao banco de dados e drenagem superficial do Ceará, auxiliando ao professor a ensinar aos alunos sobre os recursos hídricos do Estado. 

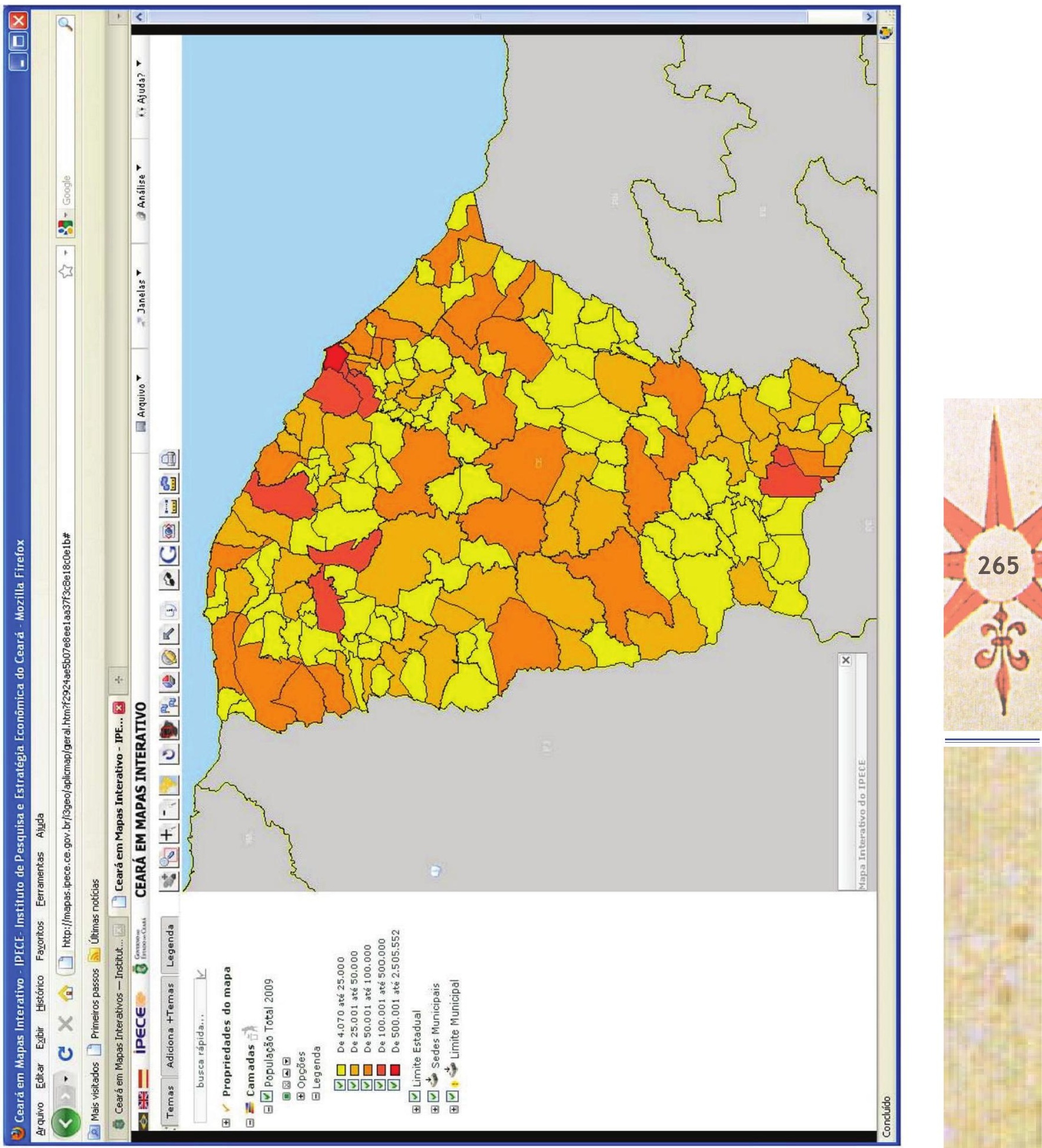

Figura 7 - Distribuição da população total de 2009 do Estado do Ceará por município. 


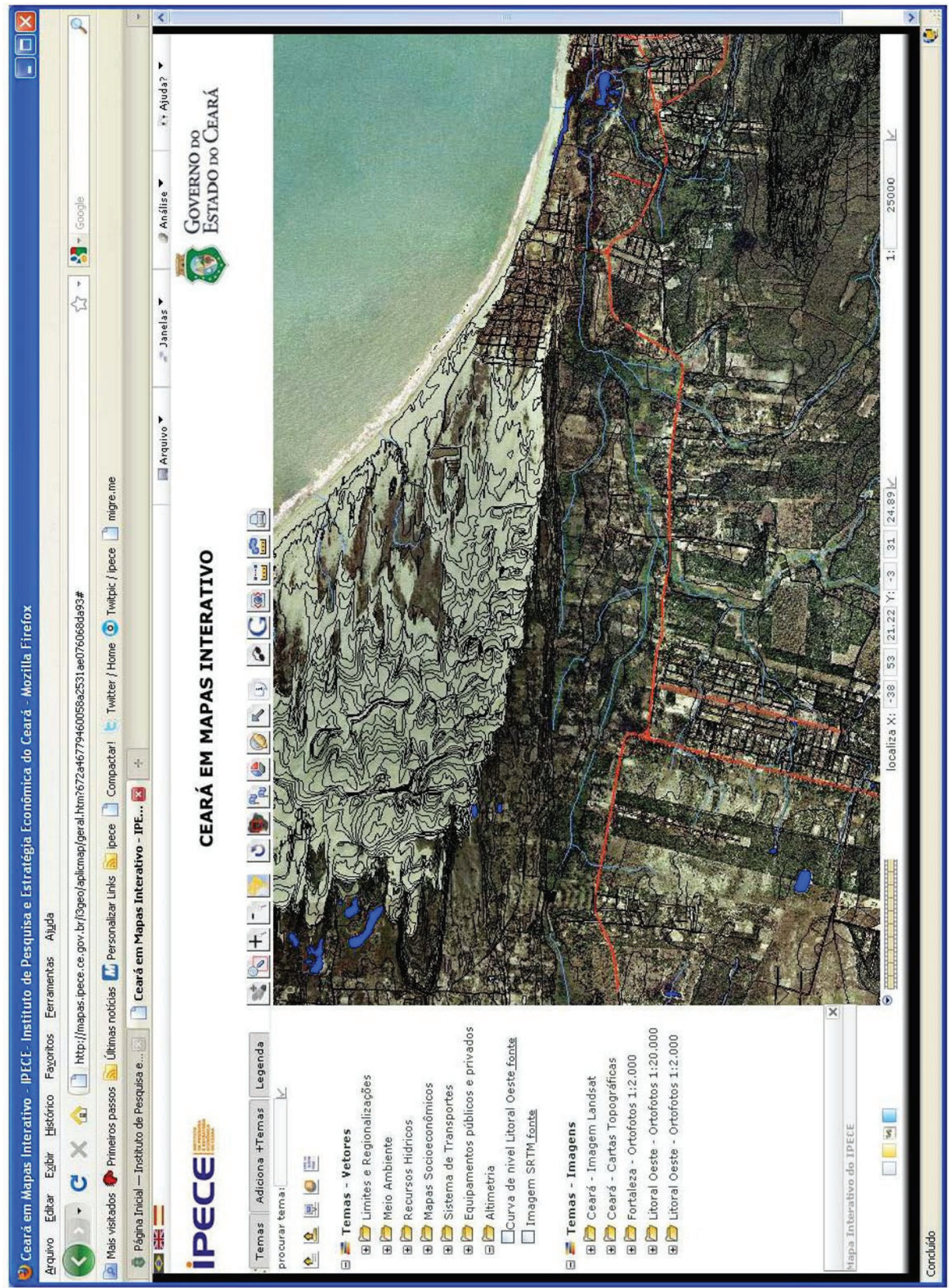

Figura 8 - Exemplo de Ortofoto com as camadas das vias de acesso, rios e curvas de nível na escala 1:25.000. Possibilidade de consulta às informações e visualização de detalhes do terreno

Além dos dados georreferenciados existentes no Sistema, os professores e alunos também podem inserir dados externos através de arquivos DBF (Data Base Format) e arquivos shapefile. O usuário do SIG-WEB Ceará em Mapas Interativo também pode acessar o banco de dados georreferenciado (imagens e vetores) em sistemas SIG Desktop, tais como o gvSIG®, Quantum GIS ${ }^{\circledR}$ ou o ArcGIS®. Para tanto é necessário se realizar uma conexão WMS (Web Map Service). 
Vale salientar que uma conexão WMS consiste em um padrão da OGC (Open Geospatial Consortium), o qual especifica o comportamento de um serviço que permite visualizar e consultar mapas. O serviço WMS possibilita visualizar informação geoespacial em geral e consultar as entidades mostradas num mapa vetorial, permitindo superpor dados vetoriais a dados matriciais em diferentes formatos, sistemas de referência de coordenadas e projeções, situadas em diferentes servidores. As petições WMS podem ser feitas por um navegador padrão em forma de URLs (Concar, 2010).

Outra informação fundamental no Sistema SIG-WEB citado refere-se aos metadados. Segundo Concar (2010), os metadados constituem o conjunto de informações descritivas sobre os dados, incluindo as características do seu levantamento, produção, qualidade e estrutura de armazenamento, essenciais para promover a sua documentação, integração e disponibilização na cartografia escolar, como também de sua real representação no plano virtual.

\section{CONSIDERAÇÕES FINAIS}

A guisa de uma conclusão para este artigo, tendo em vista um árduo trabalho de leitura e manipulação das informações do SIG-WEB Ceará em Mapas Interativo, pode-se delinear que essa ferramenta mostra-se com um potencial extraordinário para o ensino-aprendizado na cartografia escolar, com destaque para a Geografia do Estado do Ceará, bem como de outras ciências afins, haja vista a riqueza dos dados ambientais, geográficos, sociais, econômicos e estatísticos, bem como o resultado da sobreposição desses, sendo uma valiosa ferramenta voltada para a análise das informações georreferenciadas e dos indicadores geosocioeconômicos do território cearense de maneira rápida, precisa e sem custos adicionais, corroborando assim como um instrumento valioso para o ensino-aprendizado.

Neste contexto, o público beneficiado diretamente com o citado SIG-WEB consiste na população de uma maneira geral, representada em vários segmentos da sociedade, tais como: Pesquisadores, Professores, Estudantes, Universidades, Empresas públicas e privadas, ONGs, etc., os quais têm acesso às informações socioeconômicas e ambientais georreferenciadas e atualizadas do Estado do Ceará.

Como visão de futuro, o sistema Ceará em Mapas Interativo pode servir de piloto para a implantação de uma Infra-Estrutura de Dados Espaciais (IDE) no Estado do Ceará e, conseqüentemente, para o Brasil. Uma IDE tem por objetivo unificar as informações georreferenciadas produzidas pelos órgãos públicos e, até mesmo privados, em um banco de dados geográfico, disponibilizando o acesso aos dados e metadados (fonte dos dados) na internet através de um sistema de informações georreferenciadas interativo, visando à tomada de decisão dos gestores administrativos e facilitando no ensino-aprendizado da cartografia escolar nos níveis fundamental, médio e superior, assim como permitindo o planejamento e o monitoramento das ações governamentais (CONCAR, 2010).

A facilidade de se obter uma geoinformação é uma questão importante que vem se desenvolvendo e se consolidando nos últimos anos. Através da internet é possível disponibilizar dados geográficos e entre outras milhares de variáveis possíveis, por meio de aplicações de geoprocessamento. Vale salientar que as suas ferramentas podem ser utilizadas para diversas áreas do conhecimento, inclusive na cartografia escolar, viés delineador do presente artigo.

Nessa perspectiva, vale corroborar que as ferramentas SIG são de significativa importância na tomada de decisões, com destaque para as potencialidades do SIG-WEB Ceará em Mapas Interativo, que vem tornando-se cada vez mais presente em aplicações nos diversos segmentos da sociedade e das instituições públicas e privadas, tendo em vista o seu caráter multifinalitário e multidisciplinar. 
Nesse sentido, dentre os resultados almejados, demonstra-se às possibilidades de utilização da Cartografia e da Geografia associadas à Internet, materializadas em um ambiente que propicia o ensino e interpretação de mapas a partir de representação geocartográfica, multisensorial e interativa.

Por fim, percebeu-se que o uso de geotecnologias, no caso o SIG-WEB Ceará em Mapas Interativo, no ensino de Geografia, além de tornar o estudo mais dinâmico, aguça o interesse dos alunos na aquisição de informações sobre a sua cidade, região ou Estado, contribuindo para amenizar a quantidade e/ou inexistência do quadro de mapas, que na maioria das vezes encontra-se em precárias condições de conservação nas diversas instituições educacionais do interior, bem como, permite a constante atualização dos mesmos, tendo em vista que a proposta primordial do mencionado sistema é esse, pois o espaço geográfico está em constante modificação.

Conclui-se que o uso das geotecnologias computacionais no ensino-aprendizagem na Geografia, a partir do delineamento da Cartografia digital e interativa, tem possibilitado a combinação de dados e mapas com outras mídias, tornando as aulas e o aprendizado mais dinâmicos e interativos, acompanhando a tendência do mundo moderno.

O Sistema Ceará em Mapas Interativo está disponível no site do IPECE (www.ipece.ce.gov. br) ou diretamente no link http://mapas.ipece.ce.gov.br.

\section{AGRADECIMENTOS}

Agradecemos ao Instituto de Pesquisa e Estratégia Econômica do Ceará - IPECE pelo apoio e incentivos dados ao desenvolvimento desse trabalho.

\section{REFERÊNCIA BIBLIOGRÁFICA}

ANTONELI, V; THOMAZ, E.L. Caracterização do meio físico da bacia do Arroio Boa Vista, Guamiranga-PR. Rev. Caminhos da Geografia, Uberlândia, v.8, n.21, p46-58, jun. 2007. 5, n. 9, p.1661-1672, 2004.

BRASIL. Ministério da Educação - MEC. Lei no 9.394 de 20 de dezembro de 1996. Lei de diretrizes e bases da educação nacional (LDB). Estabelece as diretrizes e bases da educação brasileira. Disponível em: http:// www.mec.gov.br/legis/pdf/ lei9394.pdf. Acesso: 11/08/2010.

BRASIL. Ministério da Educação - MEC. Parâmetros Curriculares Nacionais ( $1^{\mathrm{a}}$ a $4^{\mathrm{a}}$ séries). Brasília: MEC/SEF, 10 volumes, 1997a. Disponível em: http://portal.mec.gov.br/seb/arquivos/pdf/livro01.pdf. Acesso em: 15/02/2011.

BRASIL. Ministério da Educação - MEC. Parecer CEB 04/98. Diretrizes Curriculares Nacionais para o Ensino Fundamental. Brasília: Câmara de Educação Básica do Conselho Nacional de Educação, 1998. Disponível em: http://portal.mec.gov.br/seb/ arquivos/pdf/geografia.pdf. Acesso: 15/02/2011.

BRASIL. Ministério da Educação - MEC. Ministério da Educação. Secretaria de Educação Média e Tecnológica. Parâmetros Curriculares Nacionais: Ensino Médio. Brasília: MEC/SEMT, 1999.

BRASIL. Ministério da Educação - MEC. Parâmetros Curriculares Nacionais - Ensino Médio. Brasília: MEC, 2000. Disponível em: http://portal.mec.gov.br/seb/arquivos/pdf/blegais.pdf. Acesso em: 15/02/2011. BRASIL. Ministério da Educação - MEC. Casa Civil. Decreto no 5.622, de 19 de dezembro de 2005. Regulamenta o art. 80 da Lei no 9.394, de 20 de dezembro de 1996, que estabelece as diretrizes e bases da educação nacional. Disponível em: http://www.planalto.gov.br/ccivil_03/_Ato2004-2006/2005/Decreto/ D5622.htm\# art37. Acesso: 02/04/2007.

BURROUGH, P.A. Principles of geographical information systems for land resources assessment. Oxford: Claredon Press, 1987.

CÂMARA, G., CASANOVA, M.A., DAVIS JUNIOR, C., VINHAS, L., QUEIROZ, G. Bancos de Dados Geográficos. Curitiba: Editora MundoGEO, 2005. 
CÂMARA, G., CASANOVA, M., HEMERly, A., MAGAlHÃes, G., MEDEIROS, C. Anatomia de Sistemas de Informação Geográfica. Campinas, São Paulo: Instituto de Computação, UNICAMP, 1996.

CONCAR - Comissão Nacional de Cartografia, 2010. Plano de Ação para Implantação da Infraestrutura Nacional de Dados Espaciais. Disponível em: http://www.concar.ibge.gov.br. Acesso em: 22/03/2010.

FRAGOSO, Suely. De interações e interatividade. 2001. Encontro Anual da Associação Nacional dos Programas de Pós-Graduação em Comunicação, X, 2001, Brasília. Disponível em: $<$ http://www.miniwebcursos.com.br/artigos/ PDF/interatividade.pdf> Acesso em: 16/02/2011.

HUBNER, C. E. OLIVEIRA, F.H. Gestão da Geoinformação em Implementações Multiusuários. In: Congresso Brasileiro de Cadastro Técnico Multifinalitário. COBRAC-2008. Florianópolis: UFSC, 2008. Anais... Florianópolis: Universidade Federal de Santa Catarina. 1-10p.

JUNQUEIRA, A. L. N. Sensoriamento Remoto como Recurso Interdisciplinar. 2008. Disponível em:<http://www.senac.br/pos-rede/textos/ead/2006/EAD-AnaLucia-final.pdf. Acessado em: 17/02/2011. 20 p. MEDEIROS, C. N. de. ARAGÃO, M. C. A. GOMES, D. D. M. "Ceará em Mapas Interativo - sistema de informações geográficas na Internet utilizando software livre”. In: Anais XXIV Congresso Brasileiro de Cartografia, 2010, Aracaju - SE.

MOREIRA, S. A. G. "Cartografia multimídia: possibilidade para a produção de novos conhecimentos geográficos. In: Anais XXIV Congresso Brasileiro de Cartografia, 2010, Aracaju - SE. Anais

RAMOS, C. S; SANCHEZ, M. C. Estudo metodológico de classificação de dados para cartografia temática. Geografia, Rio Claro, vol.25(2): 23-52, agosto 2000.

RIBEIRO, G. e G. CÂMARA. Arquitetura de Sistemas de Informação Geográfica. 2003. In: Introdução à Ciência da Geoinformação. Disponível em: <http://www.dpi.inpe.br/gilberto/livro/introd/cap3-arquitetura. pdf $>$. Acesso em: 17/02/2011

SANCHO, Juana Maria. Para uma Tecnologia Educacional. Porto Alegre: Artmed, 1998. (Tradução Beatriz Afonso Neves).

SILVA, M.R. Desenvolvimento de uma aplicação SIG-WEB voltada ao turismo. João Pessoa - PB: Centro Federal de Educação Tecnológica - CEFET, 2007.

XAVIER-DA-SILVA, J. Geoprocessamento para Análise Ambiental. Rio de Janeiro, 2001.

Trabalho enviado em dezembro de 2011

Trabalho aceito em janeiro de 2012 